\title{
Two new genera and two new species of Delphacidae (Hemiptera: Fulgoroidea) from China
}

\author{
DAO-ZHENG QIN \& YA-LIN ZHANG
}

Key Laboratory of Plant Protection Resources and Pest Management of Ministry of Education, Entomological Museum, Northwest A \& F University, Yangling, Shaanxi Province, 712100, China

E-mails: qindaozh0426@yahoo.com.cn,yalinzh@yahoo.com.cn

\begin{abstract}
Two new genera, Ramidelphax and Consociata, from southern China, are proposed within Delphacidae, based on the new species Ramidelphax albistriata n. sp. (from Hainan and Guizhou Provinces, China) and Consociata sinensis n. sp. (from Hainan Province, China). Because of the presence of the post-tibal spur, the new genera should be placed in the tribe Delphacini.
\end{abstract}

Key words: Hemiptera, Delphacidae, Delphacini, planthopper, new genera, new species, China

\section{Introduction}

The planthopper family Delphacidae, with more than 2000 described species in six subfamilies worldwide, is the most economically important family, as well as the largest one, of the Fulgoroidea. It is easily differentiated from other fulgoroids by the presence of a movable spur at the end of the hind tibia (Yang \& Yang, 1986). So far as the author are aware, more than 400 delphacid species belonging to five subfamilies and 129 genera are known to occur in China: three genera in Asiracinae (Liang \& Jiang, 2002), one genus in Kelisinae, three genera in Stenocraninae (Chen \& Liang, 2005), two genera in Vizcayinae (Liang \& Jiang, 2002), and 120 genera in Delphacinae, representing the richest species diversity in the world.

According to Asche (1985), the Delphacinae has been divided into three tribes: Tropidocephalini, Saccharosydnini, and Delphacini. The Chinese Delphacinae include 17 genera in Tropidocephalini (Chen, 2003), one genus in Saccharosydnini, and 102 genera in Delphacini; thus Delphacini is the largest tribe in the subfamily Delphacinae, and also the largest group of Delphacidae worldwide. The only comprehensive treatment of Chinese Delphacidae was that of Kuoh et al. (1983), which deals with 37 genera and 92 species in Delphacini. Yang (1989), Ding \& Zhang (1994), and Wang \& Ding (1996) studied the 

Delphacini include Chen et al. (2001), Chen, et al. (2001), Chen \& Ding (2002), and Qin (2005). Even so, the delphacid fauna of China is poorly known and the number of described species probably represents only a small fraction of the actual diversity of the entire Chinese delphacid fauna considering the vast territory and various complex habitats of China (Liang \& Jiang, 2002).

During recent work on the taxonomy of Delphacidae based on the Collections in the Entomological Museum, Northwest A \& F University, Yangling, Shaanxi, two new genera and two new species were found and are described below.

The type specimens for this study are deposited in the Entomological Museum, Northwest A \& F University, Yangling, Shaanxi, China (NWAFU).

The methods and terminology used in this paper follow those of Yang \& Yang (1986).

\section{Ramidelphax gen. $\mathbf{n}$.}

Type species. Ramidelphax albistriata $\mathrm{n} . \mathrm{sp}$.

Diagnosis. The genus Ramidelphax can be distinguished from other genera of Delphacini by the following combination of characters: vertex quadrate; submedian carinae uniting at extreme base of frons; frons with median carina simple; midline length of frons: greatest width about 2.4:1, widest at apex; antenna cylindrical, surpassing frontoclypeal suture; spinal formula of hind leg 5-7-4; post-tibial spur with about 30 teeth; male anal segment ring-like, lateroapical angles without spinose process; phallus tubular; genital styles rather long, widely divergent at basal half and each forked near middle.

Description. Head including eyes narrower than pronotum, vertex quadrate, longer submedially than wide at base by about 1.4:1, two lateral carina nearly parallel, submedian carinae originating near middle of lateral carinae, apical margin transverse. Y-shaped carina distinct. Frons narrower at base than at apex, midline length of frons: greatest width about 2.4:1, widest at apex, lateral carinae slightly sinuate, median carina simple, forked at extreme base, frontoclypeal suture arched upward. Postclypeus wider at base than frons at apex. Rostrum reaching to meta-coxae. Antenna cylindrical, fairly long, surpassing frontoclypeal suture, first segment about 1.9 times as long as wide, second segment about 2 times as long as first. Ocelli present.

Thorax. Pronotum slightly shorter than vertex medially, lateral carinae reaching near hind margin. Mesonotum longer on midline than vertex and pronotum together, median carina not reaching end of scutellum. Forewings long and narrow. Spinal formula of hind leg 5-7-4. Post-tibial spur with about 30 teeth.

Male genitalia. Anal segment of male short and ring-like, sunk in the emargination of pygofer, lateroapical angles roundly produced, without spinose process. Pygofer in profile with laterodorsal angle roundly produced, in posterior view with opening wider than long, without medioventral processes. Suspensorium inverted U-shaped. Diaphragm broad, in 
caudal view with dorsal margin slightly convex medially. Phallus tubular, stout and sinuated, with teeth at ventral margin of apical half. Genital styles rather long and slender, widely divergent at basal half, each forked near middle, the inner branch sharply turned lateroapically.

Etymology. The name is derived from the Latin word "rami-" (furcate), which refers to the genital styles being forked near the middle. Gender: feminine.

Distribution. Southern China (Hainan and Guizhou Provinces).

Discussion. The following are considered to be synapomorphies of this new genus: frons with median carina simple; male anal segment without spinose process; suspensorium inverted U-shaped; phallus tubular; genital styles rather long and each forked near middle, the inner branch sharply turned lateroapically.

The new genus is similar to Sogata Distant. It can be distinguished from the latter by the following combination of characters: anal segment of male short and ring-like, lateroapical angles roundly produced, without spinose process; phallus sinuate, with teeth at ventral margin of apical half, apical third not sharply turned down; suspensorium inverted U-shaped; genital styles rather long and widely divergent at basal half, forked near middle, the inner branch sharply turned lateroapically.

\section{Ramidelphax albistriata $\mathbf{n}$. sp.}

(Figs. 1-11)

Type material. Holotype-male: Liangyuan, Hainan Province, China, 2 June 1983, coll. Yalin Zhang. Paratypes-2 males: Tongshi, Hainan Province, China, 7 June 1983; 1 male: Jianfengling, Hainan Province, China, 18 May 1983, same collector as holotype; 1 male: Xiaoqikong, Guizhou Province, China, 17 September 2005, coll. Zhaofu Yang.

Description. Macropterous form (male): body length $2.4-2.7 \mathrm{~mm}$; body length including tegmen 4.3-4.9 $\mathrm{mm}$; tegmen length $3.7-4.2 \mathrm{~mm}$.

General color orange-yellow. Stem of Y-shaped carina, median carina of pro- and mesonotum ivory-white. Eyes brown. Ocelli black. Tegmen hyaline, light orange-yellow.

Structural characters as in generic description. Pygofer in profile narrow, slightly longer ventrally than dorsally, anterior and posterior margins concave. Phallus tubular, sinuated, median portion narrow, apex swollen ventrad, ventral margin with teeth at apical half. Genital styles long and slender, in posterior view widely divergent at basal half, each forked near middle, the inner branch sharply turned lateroapically. Suspensorium large, inverted U-shaped, armed ventrally, greatly incised ventrally.

Female unknown.

Etymology. The name is derived from the Latin word "alba" (white) and "striatus" (stripe), with combination of the feminine suffix "-a", which refers to the ivory-white stripe from the stem of Y-shaped carina to the end of mesonotum.

Distribution. Southern China (Hainan and Guizhou Provinces). 

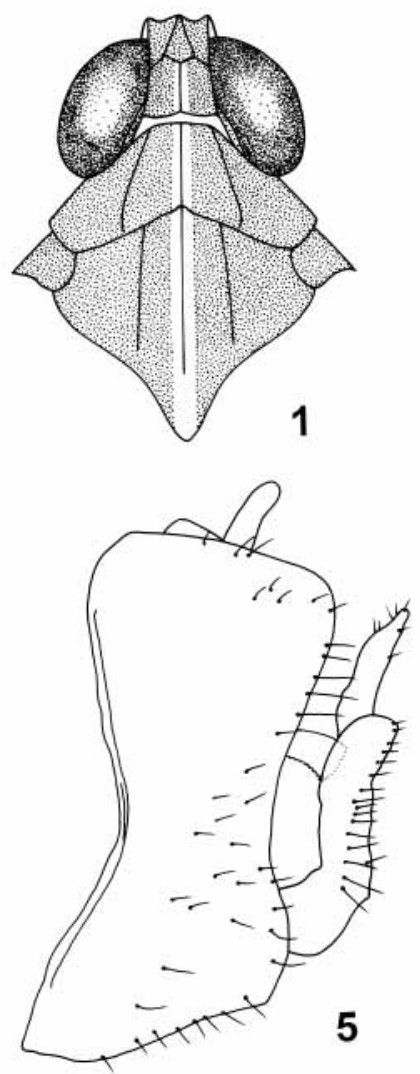

5
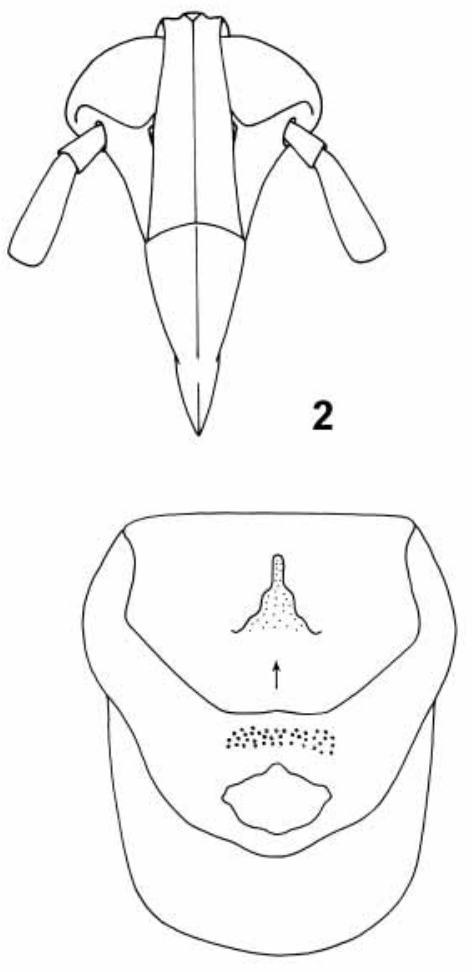

6

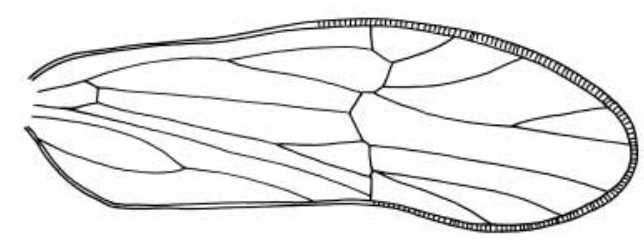

3

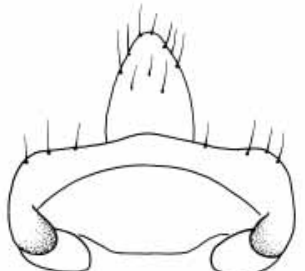

10

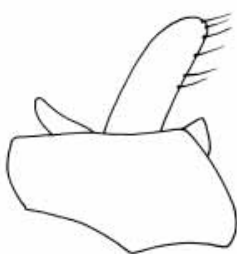

11

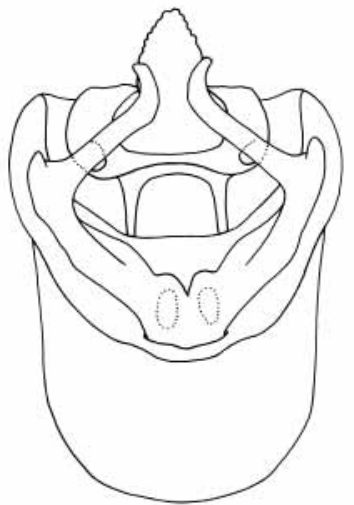

4

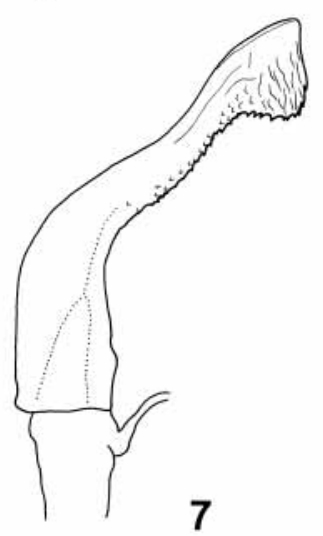

9

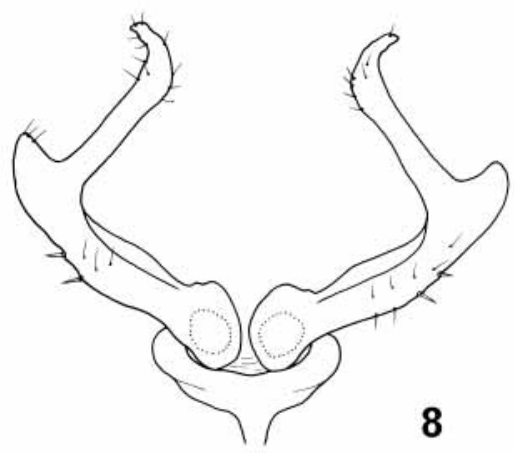

FIGURES 1-11. Ramidelphax albistriata n. sp., 1, head and thorax, dorsal view; 2, frons and clypeus; 3 , tegmen; 4, male genitalia, posterior view; 5, the same, lateral view; 6, diaphragm; 7, phallus, lateral view; 8, genital styles, caudal view; 9, suspensorium; 10, anal segment, caudoventral view; 11, the same, lateral view. 
Type species. Consociata sinensis n. sp.

Diagnosis. Consociata can be distinguished from other genera of Delphacini by the combination of the following characters: vertex with the submedian carinae not uniting at apex; midline length of frons: greatest width about $2.4: 1$, widest at apical third, median carina forked about middle level of eyes; antennae surpassing frontoclypeal suture; pronotum with lateral carinae attaining hind margin; spinal formula of hind leg 5-7-4; post-tibial spur with more than 15 teeth; male anal segment ring-like, lateroapical angles each produced into a stout spinose process; pygofer with medioventral process; phallus reflected cephalad with a process; left and right genital styles fused.

Description. Head including eyes distinctly narrower than pronotum. Vertex longer submedially than wide at base about 1.3:1, submedian carinae not uniting at apex, Yshaped carina distinct. Frons narrower at base than at apex, mid-line length of frons: greatest width 2.4:1, widest at apical third, median carina forked about middle level of eyes. Postclypeus as wide at base as apex of frons. Rostrum reaching to meta-coxae. Antenna cylindrical, surpassing frontoclypeal suture, basal segment longer than wide by about 1.5:1, shorter than second by about 1:1.8. Ocelli present.

Thorax. Pronotum slightly shorter than vertex medially, lateral carina attaining hind margin. Mesonotum in midline longer than the length of vertex and pronotum together. Spinal formula of hind leg 5-7-4. Post-tibial spur with more than 15 teeth.

Male genitalia. Anal segment of male ring-like, lateroapical angles separated, each produced into a stout spinose process. Pygofer with medioventral process. Suspensorium Y-shaped. Diaphragm broad. Phallus reflected cephalad with a process. Left and right genital styles fused.

Etymology. The name is derived from the Latin word "consociatus" (united), and with combination of the feminine suffix "-a", which refers to the left and right genital styles fused. Gender: feminine.

Discussion. The following characters are considered synapomorphies of Consociata: frons with median carina forked at about middle level of eyes; male anal segment with lateroapical angles each produced into a stout spinose process; suspensorium Y-shaped; phallus reflected cephalad with a process; left and right genital styles fused. The character of fusion of the genital styles is unique in Consociata, which can be easily separated from other genera in Delphacini.

Distribution. Southern China (Hainan Province). 
Type material. Holotype-male: Xinglong, Hainan Province, China, 23 April 1983, coll. Yalin Zhang, by light trap. Paratypes-one male; two females: same data as holotype.

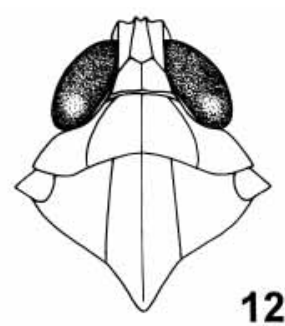

12

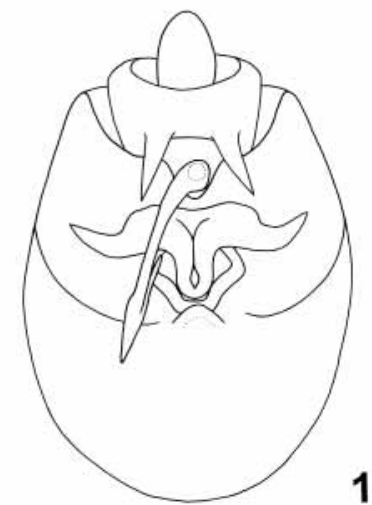

15
13
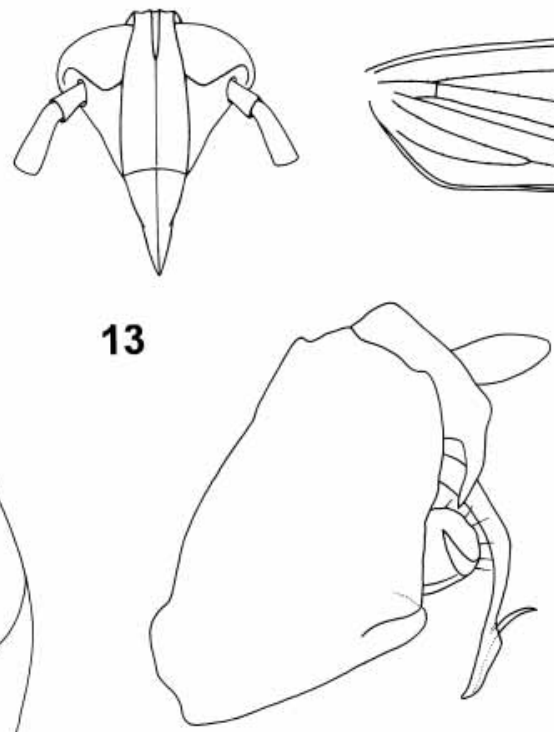

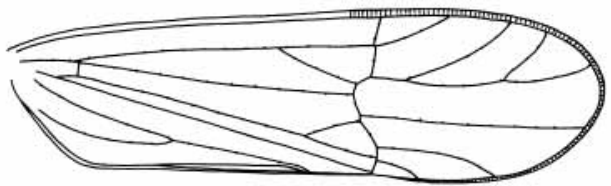

14

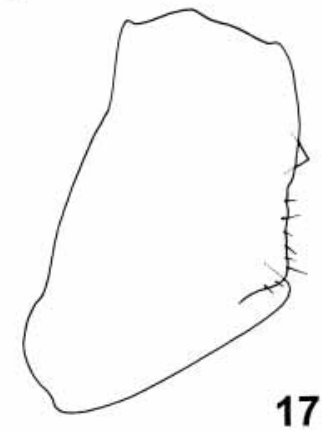

16
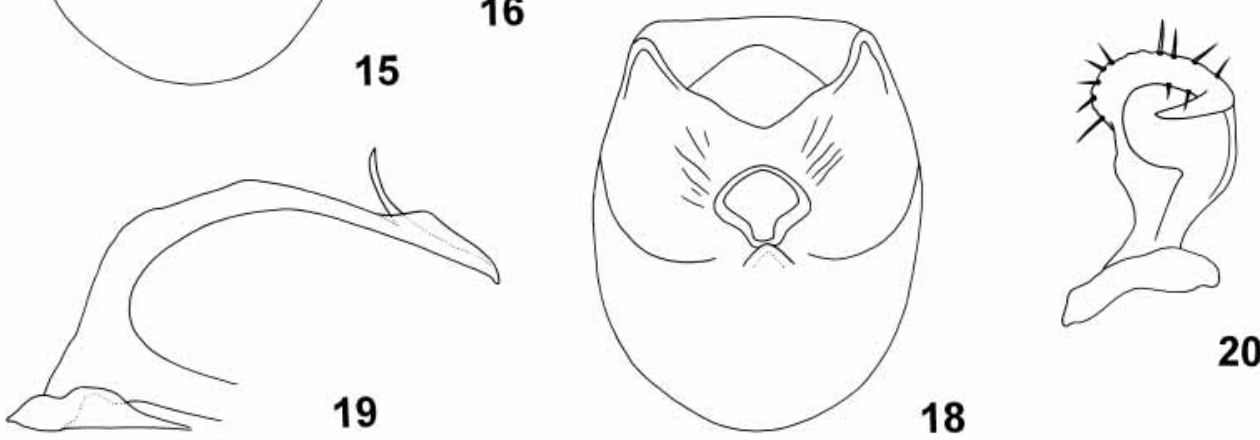

20

18

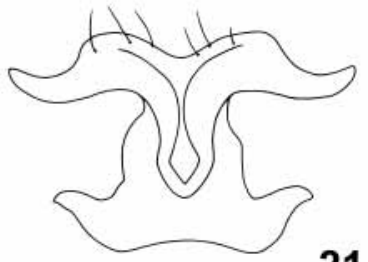

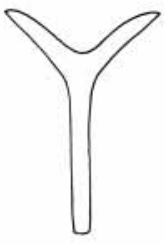

22

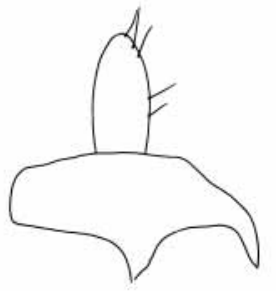

23

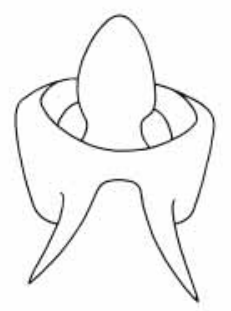

24

FIGURES 12-24. Consociata sinensis n. sp., 12, head and thorax, dorsal view; 13, frons and clypeus; 14, tegmen; 15, male genitalia, posterior view; 16, the same, lateral view; 17, male pygofer, lateral view; 18, diaphragm; 19, phallus, lateral view; 20, genital styles, caudolateral view; 21 , the same, caudal view; 22, suspensorium; 23, anal segment, lateral view; 24, the same, caudal view. 
Description. Macropterous form: body length $2.1-2.2 \mathrm{~mm}$ (male) and 2.7-2.9 mm (female); body length including tegmen 3.3-3.4 mm (male) and 3.5-3.8 mm (female); tegmen length $2.8-2.9 \mathrm{~mm}$ (male) and 2.9-3.5 mm (female).

General color orange-yellow. Eyes black. Ocelli blackish brown. Tegmen hyaline, light orange-yellow.

Structural characters as in generic description. Pygofer in profile longer ventrally than dorsally, in posterior view with opening wider than long. Phallus slender and curved, apex lamellate, reflected cephalad with a process. Suspensorium with arms about half as long as stem. Diaphragm with dorsal margin deeply concave. Opening for genital styles evenly curved at dorsal margin. Left and right genital styles fused, greatly divergent in opposite direction apically.

Etymology. The specific name refers to its distribution in China.

Distribution. Southern China (Hainan Province).

\section{Acknowledgments}

The authors would like to thank Dr. Aiping Liang (Institute of Zoology, Chinese Academy of Science, Beijing, China), Mr. Chungtu Yang (Department of Entomology, Chung Hsing University, Taichong, Taiwan, China) for copying valuable literature for this study. The first author is especially indebted to Mr. John W M Marris (Department of Entomology and Animal Ecology, Lincoln University, Canterbury, New Zealand) for helping to obtain literature during study visit to New Zealand.

\section{References}

Asche, M. (1985) Zur Phylogenie der Delphacidae Leach, 1815 (Homoptera Cicadina Fulgoromorpha). Marburger Entomological Publication, 2, 1-912.

Chen, X.S. (2003) Key to genera of the tribe Tropidocephalini (Hemiptera: Fulgoroidea: Delphacidae) from the People's Republic of China, with description of a new genus. The Canadian Entomologist, 135, 811-821.

Chen, X.S. \& Ding, J.H. (2002) One new genus and two new species of Delphacidae (Homoptera: Fulgoroidea). Acta Entomologica Sinica, 45, 226-229.

Chen, X.S., Li, Z.Z. \& Ding, J.H. (2001) Three new genera and four species of Delphacidae (Homoptera: Fulgoroidea). Acta Zootaxonomica Sinica, 26, 323-332.

Chen, X.S., Li, Z. Z., Ding, J.H. \& Chiang, S.N. (2001) New records of a genus and three species of Delphacidae (Homoptera: Fulgoroidea) from China. Entomotaxonomia, 23, 71-74.

Chen, X.S. \& Liang, A.P. (2005) A Taxonomic study of subfamily Stenocraninae (Homoptera, Fulgoroidea, Delphacidae) from China, with description of a new species of the genus Stenocranus. Acta Zootaxonomica Sinica, 30, 123-129.

Ding, J.H. \& Zhang, F.M. (1994) Delphacidae fauna of northeast China. Homoptera Fulgoroidea. Beijing, China Agriculture Science Press. 1-150.

Kuoh, C.L., Ding, J.H., Tian, L.X. \& Hwang, C.L. (1983) Economic Insect Fauna of China. Fasc. 27. Homoptera Delphacidae. Fauna Editorial Committee, Academia Sinica. Beijing, China. 
Science Press, $166 \mathrm{pp}$.

Liang, A.P. \& Jiang, G.M. (2002) Punana sinica new species and first record of the genus from China (Hemiptera: Fulgoroidea: Delphacidae). Florida Entomologist, 85, 351-355.

Qin, D.Z. (2005) A new genus and a new species of Delphacini (Hemiptera, Fulgoroidea, Delphacidae) from China. Acta Zootaxonomica Sinica, 30, 791-793.

Wang, J.C. \& Ding, J.H. (1996) Delphacidae fauna of Gansu Province, China. Homoptera Fulgoroidea. Gansu Science and Technology Press. 1-162.

Yang, C.T. (1989) Delphacidae of Taiwan (II) (Homoptera: Fulgoroidea). National Science Council Special Publication Series, 6, 1-334.

Yang, J.T. \& Yang, C.T. (1986) Delphacidae of Taiwan (I) Asiracinae and the tribe Tropidocephalini (Homoptera: Fulgoroidea). Taiwan Museum Special Publication Series, 6, 1-79. 